\title{
EDITORIAL
}

\section{Global burden of cardiovascular disease}

\section{John E Sanderson, Bongani Mayosi, Salim Yusuf, Srinath Reddy, Shengshou Hu, Zhengming Chen, Adam Timmis}

\section{See article on page 1176}

See end of article for authors' affiliations

Correspondence to: Professor J E Sanderson, Department of Cardiovascular Medicine The Medical School University of Birmingham, Edgbaston Birmingham B15 2TT, UK; i.e.sanderson@ bham.ac.uk t was estimated in 1998 that $85 \%$ of the global burden of cardiovascular diseases occurred in low and middle income countries. ${ }^{12}$ Furthermore, about half the deaths in the 1990s attributable to cardiovascular diseases in these countries were in those below the age of 70 years compared with only a quarter in the developed countries. ${ }^{2}$

Although the mortality rate of cardiovascular diseases and prevalence of major cardiovascular risk factors has generally decreased in economically developed countries, the corresponding mortality rate and risk prevalence has substantially increased in China, other East Asian societies and now India, which have been undergoing rapid demographic, social and economic changes..$^{3-5}$ Dietary and lifestyle changes associated with economic growth and increasing wealth have led to a marked increase in obesity and diabetes in Asia that may further increase the burden of cardiovascular diseases. ${ }^{6-8}$ In sub-Saharan Africa, where infectious diseases remain the leading cause of death, hypertension and stroke are emerging as an important cause of ill health in the rapidly urbanising population of the region. ${ }^{9}$ Despite these facts, the vast majority of publications in cardiovascular diseases refer to the populations of North America and Western Europe. Additionally, many of the guidelines derived from these areas are being applied, perhaps inappropriately, to other populations in completely different environments. Heart is attempting to redress this imbalance by publishing a series of invited reviews on different aspects of cardiovascular diseases in India, China, sub-Saharan Africa and South America. Emphasis is placed on local research data and practices so that these can reach a wider audience; there are many lessons to be learnt for all from practising medicine in a more resource-poor environment that concentrate the mind on doing what is most cost effective. The first in the series begins with cardiomyopathies and pericarditis in Africa, which are major causes of heart failure (see article on page 1176). ${ }^{10}$

We thank our many contributors for finding time in their busy clinical schedules to produce these reviews and we hope that our readership will find the articles as interesting and illuminating as we have as editors.

\section{Authors' affiliations}

John E Sanderson, Cardiovascular Medicine, University of Birmingham, Birmingham, UK

Bongani M Mayosi, Department of Medicine, Groote Schuur Hospital, Cape Town, South Africa

Salim Yusuf, Population Health Research Institute, McMaster University, Hamilton, Canada

Srinath Reddy, All India Institute of Medical Sciences, New Delhi, India

Shengshou Hu, Fu Wai Hospital, Chinese Academy of Medical Sciences and Peking Union Medical College,

Beijing, China

Zhengming Chen, CTSU, University of Oxford, Oxford, UK Adam Timmis, London Chest Hospital, London, UK

Conflict of interest: None declared.

\section{REFERENCES}

1 The World Health Report. Making a difference. Geneva: World Health Organization, 1999.

2 Yusuf S, Reddy S, Ounpuu S, et al. Global burden of cardiovascular diseases. Part I: General considerations, the epidemiologic transition, risk factors, and impact of urbanization. Circulation 2001;104:2746-53.

$3 \mathrm{He} J, \mathrm{Gu} D, \mathrm{Wu} X$ et al. Major causes of death among men and women in China. N Engl J Med 2005;353:1124-34.

4 Gu D, Wildman RP, Wu X, et al. Incidence and predictors of hypertension over 8 years among Chinese men and women. J Hypertens 2007;25:517-23.

5 Kearney PM, Whelton M, Reynolds K, et al. Global burden of hypertension: analysis of worldwide data. Lancet 2005:365:217-23.

6 Gu D, Reynolds K, Duan X, InterASIA Collaborative Group, et al. Prevalence of diabetes and impaired fasting glucose in the Chinese adult population. Diabetologia 2003;46:1190-8.

7 Yoon $\mathrm{KH}$, Lee JH, Kim JW, et al. Epidemic obesity and type 2 diabetes in Asia. Lancet 2006;368:1681-8.

8 Sanderson JE, Tse TF. Heart failure: a global disease requiring a global response. Heart 2003;89:585-6.

9 Opie LH, Mayosi BM. Cardiovascular disease in sub-Saharan Africa. Circulation 2005; 112:3536-40.

10 Mayosi BM. Contemporary trends in the epidemiology and management of cardiomyopathy and pericarditis in subSaharan Africa. Heart 2007;93:1176-83. 